
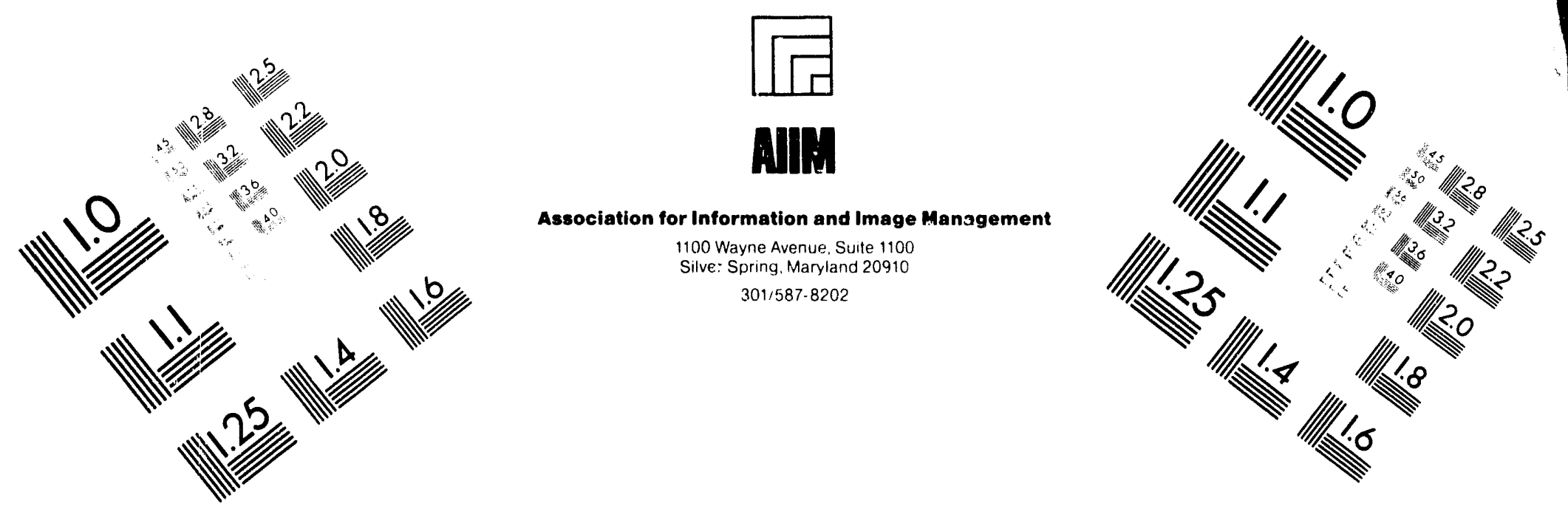

\title{
Centimeter
}

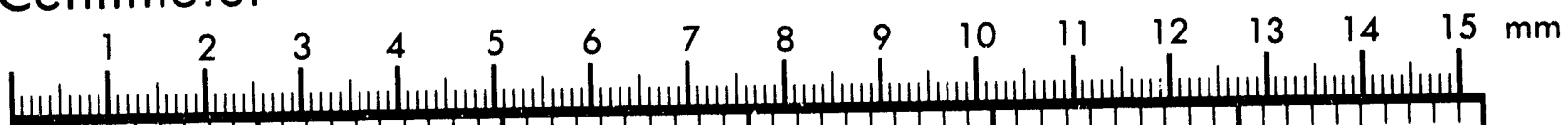

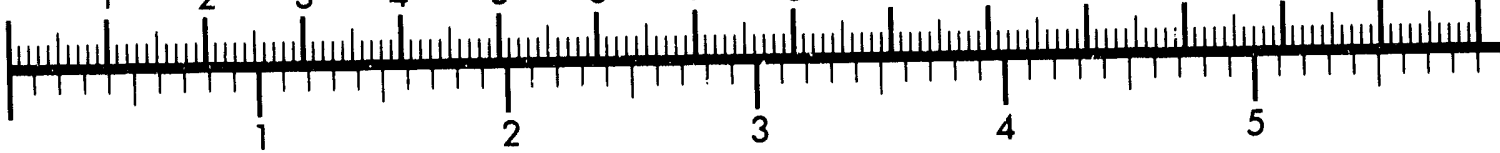
Inches
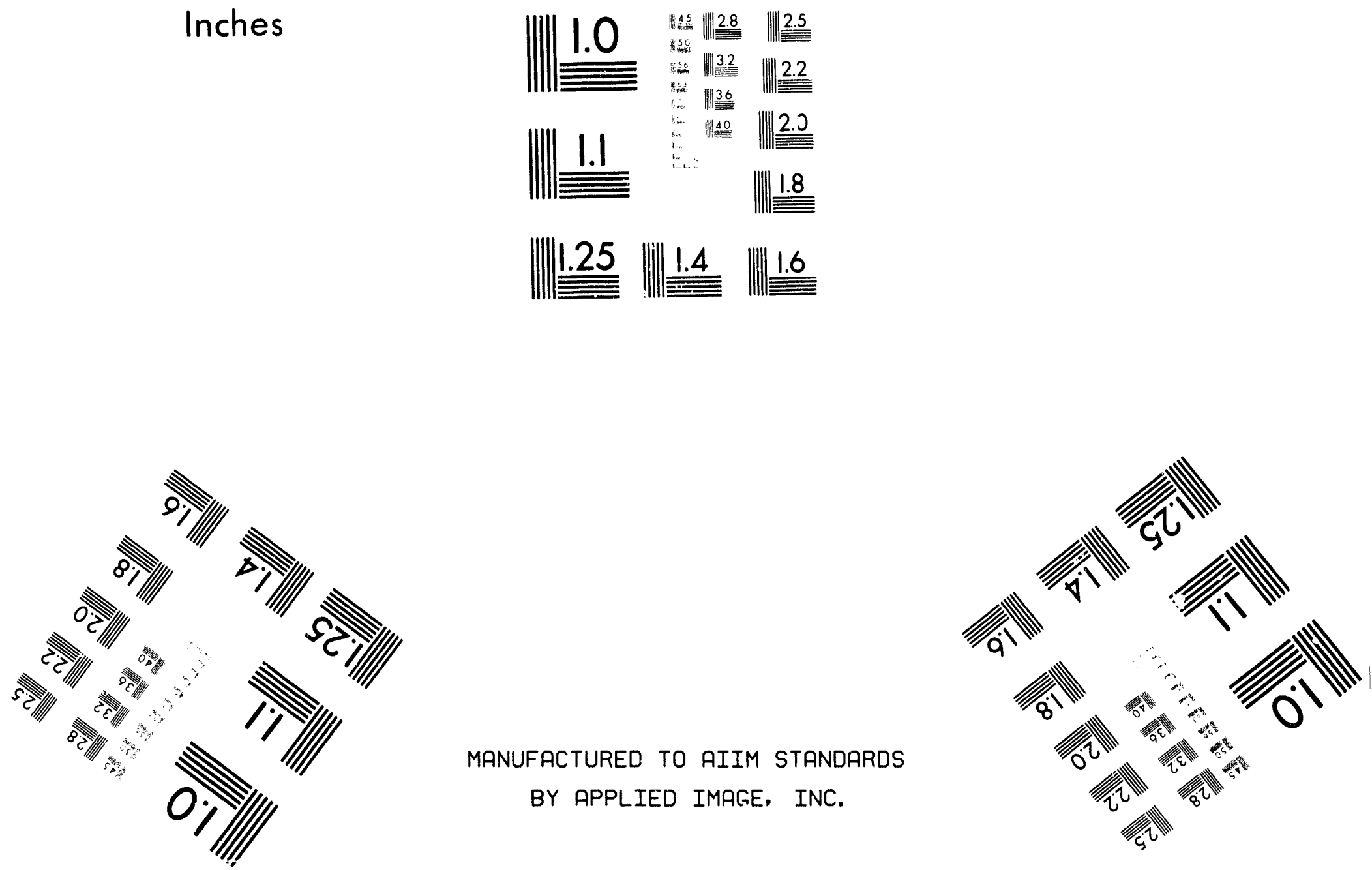

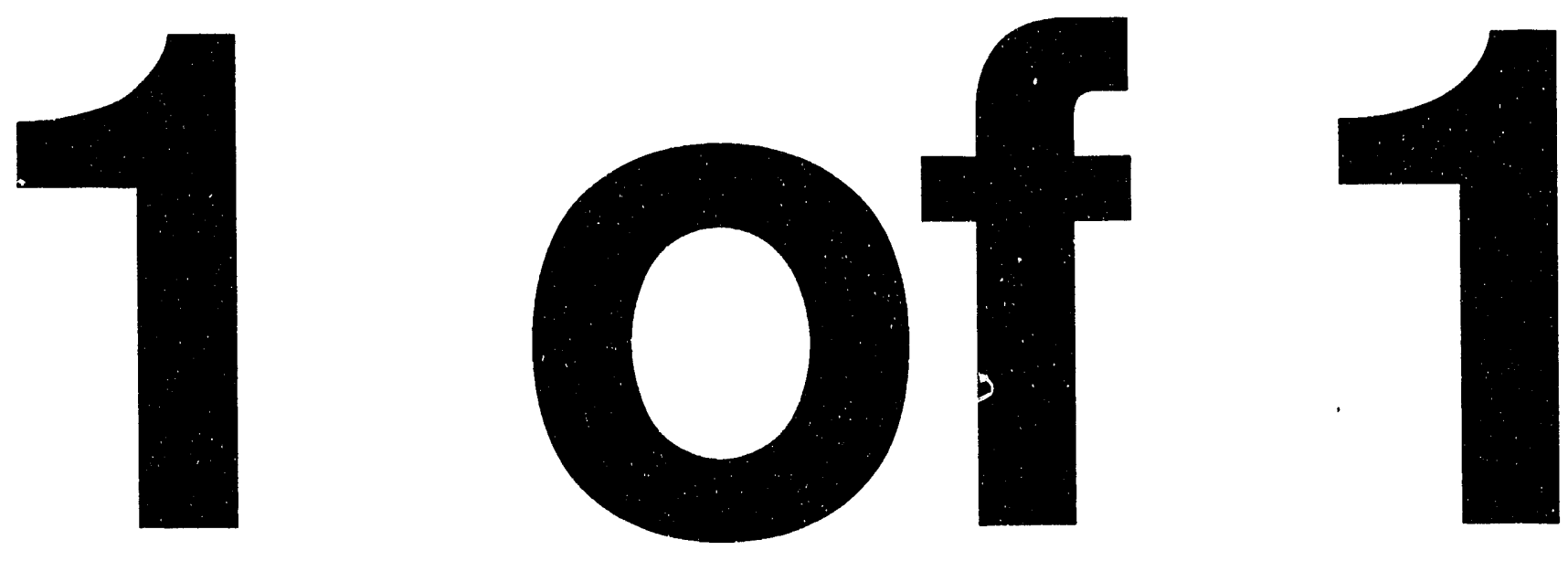
WSRC-TR-92-451

Publication Date: 10/15/92

\section{GSG-GIS Development Program Plan (U)}

\section{R. C. Lee}

Westinghouse Savannah River Company

Savannah River Site

Aiken, SC 29802

Prepared for the U. S. Department of Energy under contract No. DE-AC09-89SR18035 
Domane- Shedoner

D. B. Moore-Shedrow, Sect100 Marager

Authorized Derivative Classifier

WE8TIYOEOU8E 8ATAMAAR RIVER COYPANY

IXIER-OTICE MERORNADOS

WERC-TR-92-451

Saptember 21, 1992

To: D.B. Moore-Shedrow, 773-A

Brom: R.C. Lee, 773-42A ReL

ce: D.E. Stephenson, 773-42A

D.E. Gordon, 742-A

B.C. Goodson, 773-42X

J.E. Bolen, 703-41A

H.N. Kennedy, 704-49B

T.v. Crawtord, 773-A.

B.J. Gutlerrez, 703-421

T.J. Tamples, 703-4L

S.K. KLmball, DOE/DP-621

K.W. Barlow, 704-498

R.T. Jones, NPR

ce: (w/0 attachment)

J.D. Cardson, 706-13C

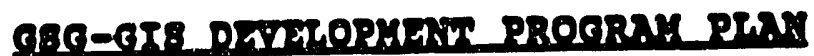

At the request of DOE/DR, the Salsmology Group of Enviromiantal seiences section have prepared a Program Plan (see attached) $20 r$ the development of a Geologic, seismological, and Geotechnical (GSG) data base on a Geographic Ineormation syatem (GIS). The data base and associated graphical syotems to be developed in this plan will be useful to DOE and WSRC management for the integration and coordination of SRS geological programs.

This plan also meets an agreed-upon deliverable to the Detense Nuclear Facillties Safaty Board. Schedules for tasks in the plan are dependent upon timely contractual arrangements to be made by WSRC Procurement.

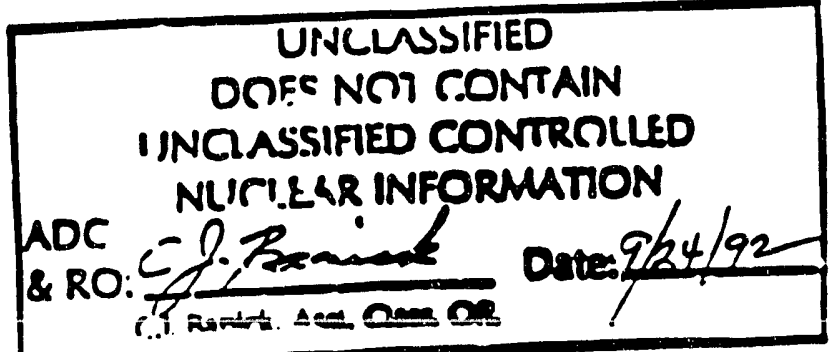




\section{CONTENTS}

Program Summary..................................................................................................... 1

Introduction ...................................................................................................... 2

Geographic Information System and Related Systems

at the Savannah River Site......................................................................................... 3

GSC Data at the Savannah River Site ............................................................. 4

GSG Data Requirements and Priorities (SCOPE).................................................... 4

Graphical Geographic Information System, and Computational

Requirements of the System ............................................................................. 5

GSG Data Base Development Task Descriptions .................................................. 5

References........................................................................................................................... 7

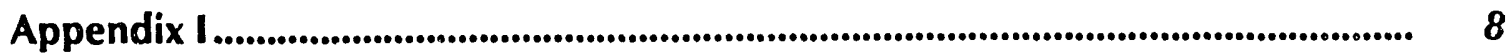

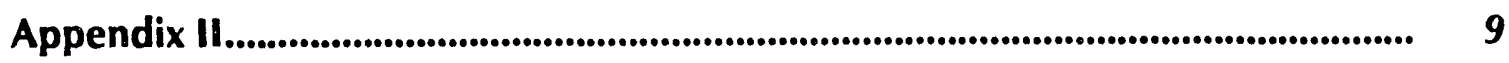

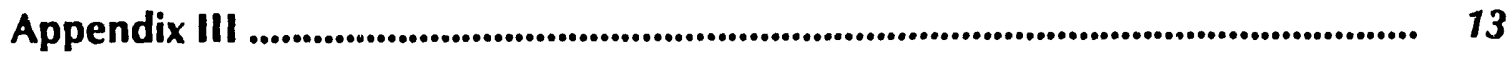

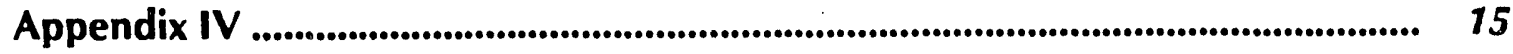

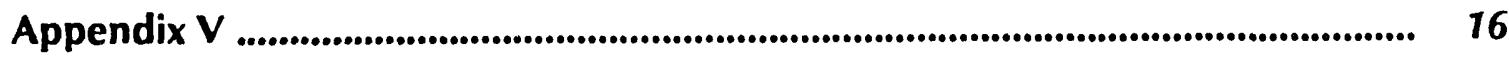




\section{GSG-GIS Development Program Plan(U)}

\section{Program Summary}

For the past 40 years, the Savannah River Site (SRS) has been subjected to numerous geological and geotechnical investigations in support of facility construction and waste site development and remediation. Over this period, a variety of different subcontractors have collected large quantities of geoscience data. In addition, current programs involve numerous investigators from different departments, and consequently, earth science data and interpretations are scattered among the departments, investigators, and subcontractors at SRS. As a result, scientific and management decisions cannot take advantage of the significant body of information that exists at SRS. Recent DOE Orders (Systematic Evaluation Program, 1991) have put specific requirements on their contractors to compile geological databases to coordinate DOE site data gathering and interpretations, and to assist in compiling safety analysis reports. The Earth Science Advisory Committee and the Environmental Advisory Committee have also made specific recommendations on the management of SRS geoscience data. This plan describes a management system to identify, communicate, and compile SRS genlogical (including geohydrologic), seismological, and geotechnical data and interpretations on a Geographic Information System. 


\section{Introduction}

This program plan will result in a geotechnical database (GDB) configured to reside on a Geographic Information System (GIS), which will be operated by DOE/WSRC. The database is described as geological, seismological, and geotechnical (including geophysical) data, interpretations, and data acquisition locations as graphically represented "data layers". Relational data, in tabular or textual form, will also be considered as part the database. Geographic Information Systems, supporting hardware, and related software have been marketed for a decade by vendors to perform tasks similar to those required by WSRC. The GIS combines digital cartographic data with database management to perform storage, management, analysis, and display of locational data (Star and Estes, 1990). Because temporal attributes can be handled by GIS, seismic, groundwater, and contaminant tracking are also natural applications to the system. Costs for acquiring powerful workstations to operate GIS continue to decrease as the costs of computer memory decrease and computational speeds increase. A primary reason for compiling the GDB on a GIS is to develop, support, and maintain the geological, seismological, and geotechnical (GSG) database for the Savannah River Site (SRS) Safety Analysis Report (SAR) (Frank McCoy, letter to Paul Rice, February 28, 1992). The GDB would provide graphical depictions and a relational database applicable to the compilation of information for the SAR.

Facility site-specific, SRS specific, and regional data that can be translated to GIS data "layers" would become part of the GDB. Examples of data layers include geologic maps, well locations, seismic survey lines, and gravity and magnetic interpretative maps. Therefore, in addition to a discovery tool for management, GDB is a useful data manipulation device (e.g., the system could construct stratigraphic "fence diagrams" and material property cross section illustrations). The GIS would not only serve as a library function or a repository for GSG data, but would provide information related to that data (e.g., spatial data that may be graphically presented and 'point' to relational data such as the reference bibliography or individual/department source of the data, a different layer relating to the survey locations at data acquisition, or the quality of the data source).

In addition to its purpose as a tool to develop a generic SAR Chapter 2, the system and its organization would serve a variety of other uses, including the following: a management tool for program planning to ensure that all relevant SRS data and interpretations are considered prior to decisions on making additional geotechnical measurements that have potential significant costs; a system to rapidly overlay various data layers to resolve or address scientific issues related to, among other things, material properties and crustal structure; relational database capabilities to locate data sources not contained in the GDB or to provide a documented technical basis for management decisions; and most importantly, a management structure that can coordinate GSG operations at SRS (Earth Sciences Advisory Committee, letter to Begley, December 13, 1991).

The most difficult tasks for the integration of GSG data are those related to the development of a management system that can identify locations and status of site-related GSG data and communicate existing and future GSG data to a GIS coordinator. This plan recognizes that GSG-type data have multiple uses to numerous departments, individuals, and contractors at SRS, and, therefore, should continue to be the responsibility of those departments and individuals. The principal challenge of this plan is to provide a mechanism that will communicate subsets of geotechnical data and then perform the much simpler task of organizing the data effectively.

Hereafter, data should be taken to mean digital or analog points or representations consisting of parameters and corresponding locations; interpretations; survey locations; etc.

The necessary steps to create a GDB that are outlined in this plan are as follows:

1. Determine data types to be captured in the GIS (see Appendix II for preliminary lists).

2. Identify published or contractor reports that can be referenced, unpublished data, already prepared GIS data layers, and other GSG databases to be captured by the system (partial list in Appendix I).

3. Develop a management system to locate and determine "ownership" by departments and individuals of GSG data that may or may not have been published or intemally reported.

(Suggestions for management and a partial list of individuals and departments are contained in this report.)

4. For the estimated size of the database and user requirements of the system, determine an initial system hardware and software configuration that will be as consistent with existing databases as possible and will be easily expanded or upgraded. 
5. Develop schedule and staffing requirements for adoption or development of various layers on the system.

6. Based on schedule requirements, quantity of data, and system configuration, determine the contract basis to operate and maintain the system, select and input data layers, and provide products and training to users of the system.

7. Based on system configuration and number of personnel, determine space, data communications, power, and environment requirements.

\section{Geographic Information System and Related Systems at the Savannah River Site}

GSG data compiled on a GIS should conform to DOE requirements and be compatible with other SRS databases. Currently, information on the SRS GIS is being compiled by the GIS Task Group, headed by Don Gordon of Environment, Safety, Health, and Quality Assurance. The GIS Task Group is surveying GIS users for organization/department, responsible individual, location, hardware and software description, scope, type and description of data layers, and compatibility or exchangeability with other GISs.

Based on information collected by the task group, some preliminary information on SRS organizations (WSRC, DOE-SR, and their subcontractors) that currently procure, collect, process, or organize site data (including GSG data) into a database for GIS application is listed below. All GIS applications is compilcd on ESRI ARC/INFO systems.

\section{Savannah River Technology Center (SRTC) Environmental Sciences Section}

- H. E. Mackey: land cover including soils, vegetation, and wetlands.

\section{SRTC Environmental Technology Section}

- D. W. Hayes: surface water and land-based reference systems.

SRS Environmental Protection Department; Environmental Monitoring

- Bob Lorenz/D. J. Vaaler: groundwater quality.

\section{SRS Environmental Protection Department; Environmental Analysis}

- D. E. Gordon/Chris Arenz: regulatory mapping requirements and well construction data.

\section{Savannah River Ecology Laboratory} (SREL)

- A. E. Cook: wildlife habitat.

\section{Savannah River Forest Station (SRFS)}

- H. R. Park: wildlife/botany, including threatened and endangered species, sensitive species, and rare and sensitive plants.

SRS users of computer-aided drafting (CAD) using Intergraph are listed below.

\section{Savannah River Archaeological Research Program (SRARP)}

- M. J. Brooks: land use planning and cultural data, including archaeological and historic sites.

\section{Environmental Restoration Department (WSRC)}

- Kathy P. Brady: waste-site layers, location, and contaminant(s); site surveys.

\section{Site Engineering \& Services Department (WSRC)}

- D. M. Isiminger: land use planning, structural facilities.

Structural Mechanics has a DBASE4 summary of titles for soil studies performed onsite.

ESRI ARC/INFO is the GIS standard for the EPA and is currently in wide use at SRS. Some data layers of interest may exist on Intergraph; translation programs to communicate these layers are either available or being developed.

Other more specialized relational data and graphic systems are available with strengths in particular areas, which may be useful on subsets of data. These systems include the following: 
Geographic Resources Analysis Support System (GRASS)

- PC-based software system that has many graphical applications in environmental databases (raster based).

\section{Heuristic Optimized Processing System (HOPS)}

- MAC-based hardware/software for rapid sorting and searching of very large databases.

\section{GSG Data at the Savannah River Site}

Appendix I contains a partial list of SRS departments and individual scientists or their subcontractors that have in the past or are currently working with GSG data. There are other individuals not listed here, and there are a large number of subcontractors who maintain SRS GSG data that are not included on this list. This list serves as a starting point for potential GSG subcommittee members and the task of locating the various reports and data files.

\section{GSG Data Requirements and Priorities (SCOPE)}

In addition to specific database requests made by DOE, there are DOE requirements for specific geological databases (USDOE, 1991). These requirements, together with the Nuclear Regulatory Commission (NRC) Standard Review Plan, were used to develop a list of data types that would constitute the GSG database.

The following two documents provide supplementary guidance for DOE non-reactor facilities and supplement DOE Order 6430.1A and UCRL-15910 to ensure state-of-the-art in facility design evaluations: Guidance for Evaluation of Seismic Hazard, Systematic Evaluation Program (SEP) (1991); and Guidance for Geotechnical Studies, Systematic Evaluation Program (1991).

Section 4.1 of the SEP specifies that facility seismic hazard evaluations incorporate a geologic and seismic database. The SEP also recommends that sites that have moderate or high hazard facilities, such as SRS, maintain a comprehensive database of "geologic and seismic factors." The SEP also requires that an "accurate database" be established for the "geology, seismology, groundwater, subsurface soils and rocks, and earth materials for construction at the DOE site."
A preliminary list of these "factors" is contained in Appendix II, but include the following general areas:

- geologic maps

- active fault parameters that bear on ground motion potential

- site-specific amplification factors

- soil and rock material properties

- historical and instrumental seismicity

- geophysical data

- paleoseismic data

- seismic hazard evaluations

- geotechnical engineering (soils) parameters

- hydrology (groundwater)

The NRC Standard Review Plan, for commercial reactors, has additional GSG data requirements. They are as follows:

- site and regional geologic and seismic information in illustrative form, including location of all plant structures, borings, trenches, and profiles; relationship between site and regional geology

- vibratory ground motion: all seismic, geologic, tectonic, and wave propagation characteristics that bear on design ground motion

- surface faulting: data bearing on faulting, structural geology, observed lineaments, and exploratory methods

- geotechnical data bearing on the stability of subsurface materials and foundations and slope stability

Data layer descriptions should include the following:

- description of data or interpretation type

- data acquisition or measurement locations, date of acquisition, instrument parameters, etc., if appropriate

- identification of the report/database that contains or references the data

- any digital standards used

- identification of SRS or subcontractors that control the data or database

- estimated size of the database

- QA program, if any, involved with the data collection and archiving

- references to hard copy of report or data files

Appendix II contains greater detail on specific data layers required by regulation. 


\section{Graphical, Geographic Information System, and Computational Requirements of the System}

Based on the GIS/GSG data requirements discussed above and in Appendix II, there are several system requirements, most of which are common to modern GIS (i.e., all graphical and relational requirements can be easily met by current off-the-shelf systems). These system requirements are as follows:

- multiple coverages or layers combined or overlayed

- DBM capabilities that allow for easy correlation between cartographic and attribute data (i.e., interactively selected geographic and attribute data

- selected information plotted and printed on combined layers

- Boolean operations (addition, subtraction) on planimetric data

- contour point data from combined layers

- ability to shift, rotate, and provide numerous standard projection conversion transformations

- contouring ability that can accommodate and display faults

- contour or 3-D perspective projections from random or uniformly spaced, digital data

- tabular data and contour data to create stratigraphic fence and block diagrams

- ability to call up and display lithologic logs for several drill holes concurrently, and manipulate them to common depth points/intervals

- GIS database conversion to other industry standard systems such as AutoCAD and Intergraph

- modular hardware and software to allow expansion

- elements that are compatible on both PC/Mac and workstation

- communications to VAX cluster via ETHER-Net connection

- high resolution color interactive display and hard copy capability

More detailed system requirements are described in Appendix III.

There are several additional requirements that software vendors must meet. First, to ensure that all aspects of the software are functioning, the vendors must provide test input data that exercise all code operations. Secondly, source codes and full documentation (including verification and validation) must be on file with the vendor.

Industry standard procedures must be used in preparing data layers. Since GISs do not generate or record raw data, all digital data would be derived from previously reported and readily available reports (hard copy or digital format) or from system-derived data layers or tabular data that can be derived from data and layers in those reports. Consequently, a GIS database can always be re-created or quickly verified against the raw data source for accuracy.

\section{GSG Database Development Task Descriptions}

Task 1

WSRC would select or hire a GSG manager/ coordinator, who should possess geotechnical, earth science, and management experience. The GSG manager would be responsible for coordinating all geotechnical activities at SRS and building the GSG database.

\section{Task 2}

The WSRC GSG manager would select a subcommittee from the various organizations that collect or contract for GSG data. Each subcommittee member would be responsible for coordinating GSG activities with the GSG manager and for assistance in providing the GSG manager specific data from their organization. This data would include lists of data types, a corresponding list of references or reports, maps or tables of data acquisition parameters, physical location of the references and data, and technical interface to the database manager. This data communication would include all current and historical data that the subcommittee's group are responsible for or control.

\section{Task 3}

Staffing would require individuals with workstation and software experience. The staff would be responsible for

- maintaining the workstation hardware and software

- providing accounting services on the system.

- training users on the system.

- performing routine backups

- developing data layers and related databases (including digitizing for data entry)

- responding to requests for system products and transferring databases

- coordinating activities with the GSG manager

For these tasks, the GSG database manager, who would oversee the program and work with the GSA manager, should be a geologist with geotechnical database experience. Two senior programmer/system analysts would be required to oversee and support hardware, software, and database development 
(individuals with background in engineering, or computer science; programming ability in $\mathrm{C}$ and FORTRAN; experience with ARC/INFO; experienced with geotechnical databases). An intro-level programming position to support senior programmers and data entry (with some programming experience) would also be required.

\section{Task 4}

SRTC would acquire workstation and software and begin to assemble the database. Subcontracts would be let to assist in the acquisition of the workstation and development of regional potential field, fault, and seismic data layers. Currently, available base maps, geographic, topographic, and facility data layers would be incorporated.

The workstation would use ESRI ARC/INFO and other third-party software that meets the minimum requirements specified in Appendix III. This system has been selected because it is inexpensive, meets minimum requirements, and can be easily upgraded for unforeseen database growth and future user requirements. The strategy is to keep the up-front costs low and let system hardware and software demands by management and users drive the requisition process for other, more expensive peripherals and software. EG\&G (Las Vegas) may be selected as an integral component for database development because they have been a provider of GIS data layer production services for WSRC/ESS for several years, they are familiar with SRS databases, and they have staff familiar with ESRI software. More details on specific workstation hardware and software are contained in Appendix IV.

\section{Task 5}

The WSRC GSG manager together with the subcommittee would work jointly to set priorities on selection of dats layers to import to GIS. The highest data layer priority is the development of a graphical interface that illustrates for the user where GSG data have been collected at SRS and where the data/reports/interpretations currently reside [i.e., a geographic query system that illustrates where various subsets of data were collected onsite, and then, if queried by the user, the system points to tabular or textual data containing reference material (date, name, and location of report, department that controls the data, etc.)]. Other high priority data layers would be those related to SAR figures, K Area, and non-reactor moderate and low hazard facilities.

\section{Task 6}

Regional data layers would be compiled on the database, and SRS data acquisition maps and relational data to references would be prepared. Strategy and priority for incorporating the balance of the desired data would be developed.

\section{Task 7}

New and existing GSG data would be continually compiled on the system. A GSG data maintainer would be selected to take control of the GSG database, archive, and update the data.

A time frame for the seven tasks is provided in Appendix V. 


\section{References}

Kennedy, R. P., et al. (1990). Design and Evaluation Guidelines for Department of Energy Facilities Subjected to Natural Phenomena Hazards. UCRL-15910, Lawrence Livermore National Laboratory, Livermore, CA.

U.S. Department of Energy (1989). General Design Criteria. DOE Order 6430.1A, Washington, DC.

U.S. Department of Energy (1991). Guidance for Evaluation of Seismic Hazard. Systematic Evaluation Program, Department of Energy NonReactor Facilities.
U.S. Department of Energy (1991). Guidance for Geotechnical Studies. Systematic Evaluation Program, Department of Energy Non-Rcactor Facilities.

U.S. Nuclear Regulatory Commission. Standara' Review Plan. NUREG-0800, Washington, DC. 


\section{Appendix 1}

The following contains a list of individuals and organizations that have access to or control GSG data either by acquisition of the data, storing or archiving the data, processing and interpreting the data, or contracting for the data collection. These organizations and individuals are exclusive of the groups preparing GIS data layers identified above.

\section{WSRC Structural Mechanics}

- Nick Kennedy: preparation of geotechnical database for S, H, M, A, and F Areas non-reactor facilities

- Chester Reeves: collection and preparation of a geotechnical database for $\mathrm{K}$ Area (reactor facilities)

- George Glos: Bechtel engineer charged with building geotechnical database

\section{WSRC Environmental Monitoring}

- Van Price: geological, geophysical

- Janelle Jenson: drilling and geophysical logs

- Terrence Killeen: monitoring well information

- Paul Thayer: UNC sedimentologist, core log data

- Andy Smits: SAIC geologist, core log data

- John Marsh: subcontractor, core log database

- Randy Cumbest: geology

\section{WSRC Environmental Sciences}

- Dale Stephenson: geological/geotechnical/ hydrological data and interpretations

- Alice Stieve: geologic/geotechnical data and interpretations

- Rolf Aadland: geologic and hydrological data and interpretations, seismic reflection data

- John Haslow: groundwater flow data and interpretations

- Carol Eddy/Ralph Nichols: 2-, 3-D models and environmental database $(\mathrm{F} / \mathrm{H}, \mathrm{D}, \mathrm{A} / \mathrm{M}, \mathrm{TNX})$

- Virgil Rogers: soil and wetlands map

- Richard Strom: geochemical

\section{WSRC Environmental Restoration}

- Charlie Sherman

- Doug Wyatt: geophysical data

- Mary Harris: stratigraphy, geophysical logs, core $\log$ data, waste site data

- Scott McMullen: geology

- Kathy Brady: ER database developnent

- Catherine Lewis: sedimentology, geology, hydrogeology

- Sharon Lewis: structural geology, hydrogeology

- Neil O'Halloran: core logging contracts with SAIC

- Tim Gaughan: geology, seismic reflection data

- Gerald Blount: geology

- Jay Horvath: manages ER programs, geochemistry

- Steve Bartlett: geotechnical

- Mary Flora: geohydrology

- Chris Bergren: geohydrology

WSRC Interim Waste Technology

- Jim Cook: geology

- Bob Hiergesell: geology, groundwater

\section{WSRC Environmental Protection} Department

- Chris Bennett: geophysical data

- Terresa Jordan: well location data

\section{DOE/SR}

- Brent Gutierrez: geotechnical

- Tom Temples: geophysics

- Jim Bolen: geology

- Tom Hicks: geohydrology 


\section{Appendix II}

This appendix identifies specific data types to be imported into the GIS/GDB. The layers were selected from DOE Orders, NRC Standard Review Plan, and drawn from typical illustrations from SRS SARs. Specific database requirements were taken from the following:

- Guidance for Evaluation of Seismic Hazard, Systematic Evaluation Program (1991)

- Guidance for Geotechnical Studies, Systematic Evaluation Program (1991)

- NRC Standard Review Plan: 2.5.1, Basic Geologic and Seismic Information; sections 2.5.1, Site Geclogy; 2.5.2, Vibratory Ground Motion; 2.5.3, Surface Faulting; 2.5.4, Stability of Subsurface Materials and Foundations; 2.5.5 Stability of Slopes; 3.7.1, Seismic Design Parameters
Table 1 contains the minimum data layer types to be incorporated into the GIS/GSG database. The Layer Description column represents the type of GSG data that would be represented in a graphical form, either in plan, cross-section, or perspective view, or combination. Note that any $2-D$ plan view layer may be viewed or operated on by any other combination of layers. The relational data/other layers illustrate the relational data (in textual, tabuler, or visual form) that would be associated with the data layers. The Regional, SRS, and Site Specific columns represent the scope of the data layer.

All data layers and relational data will have data source references and location of hard copy. 


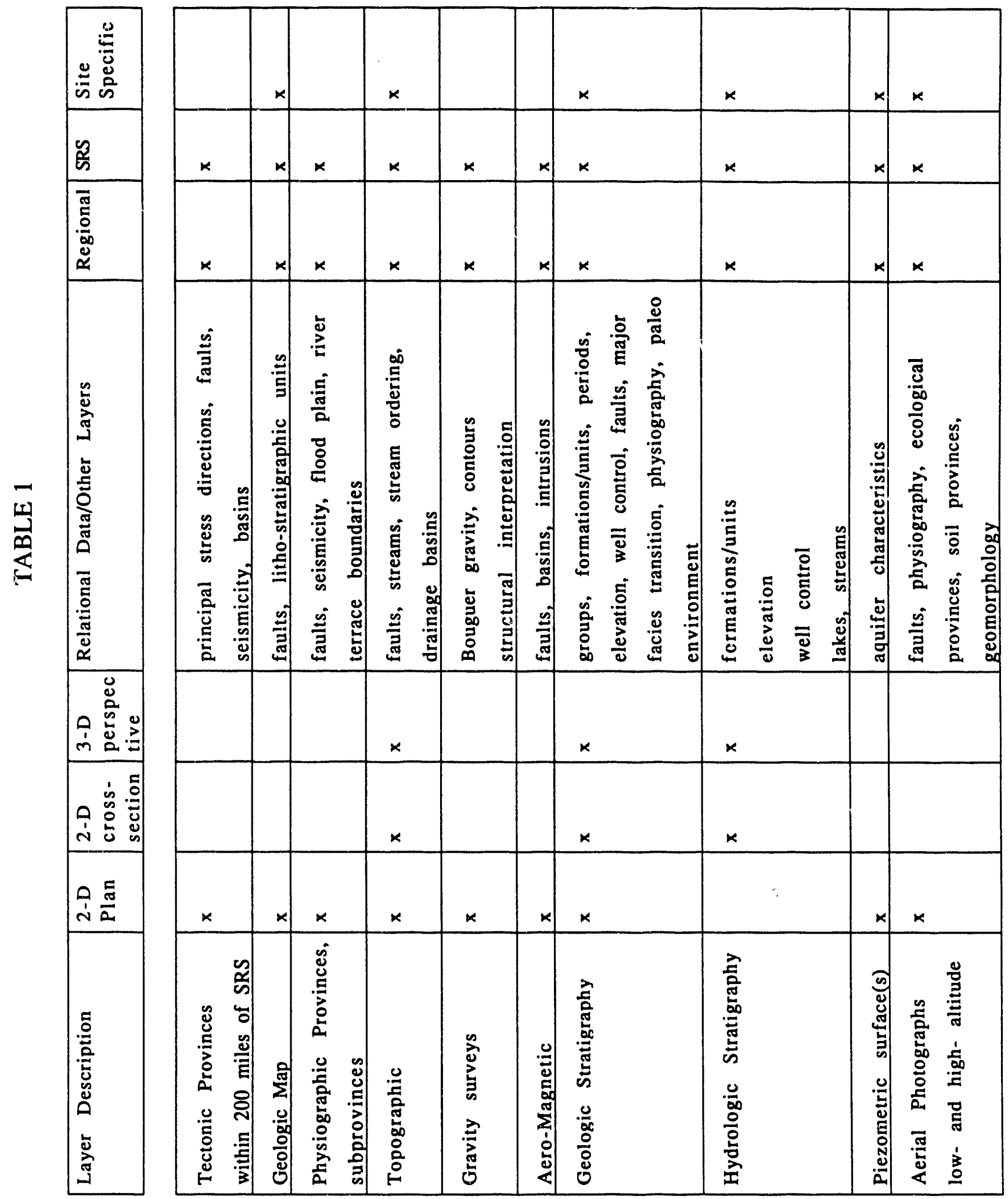




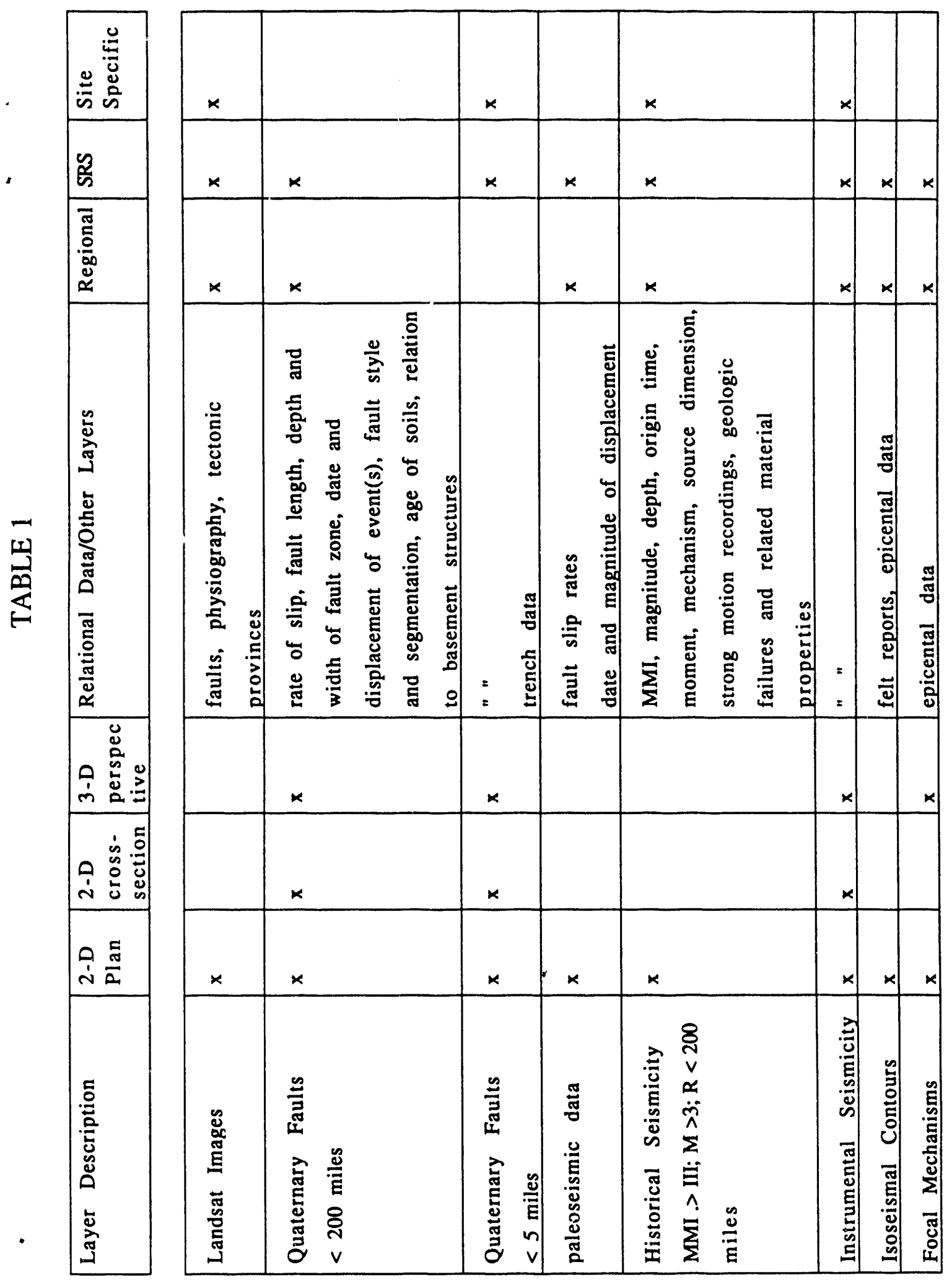




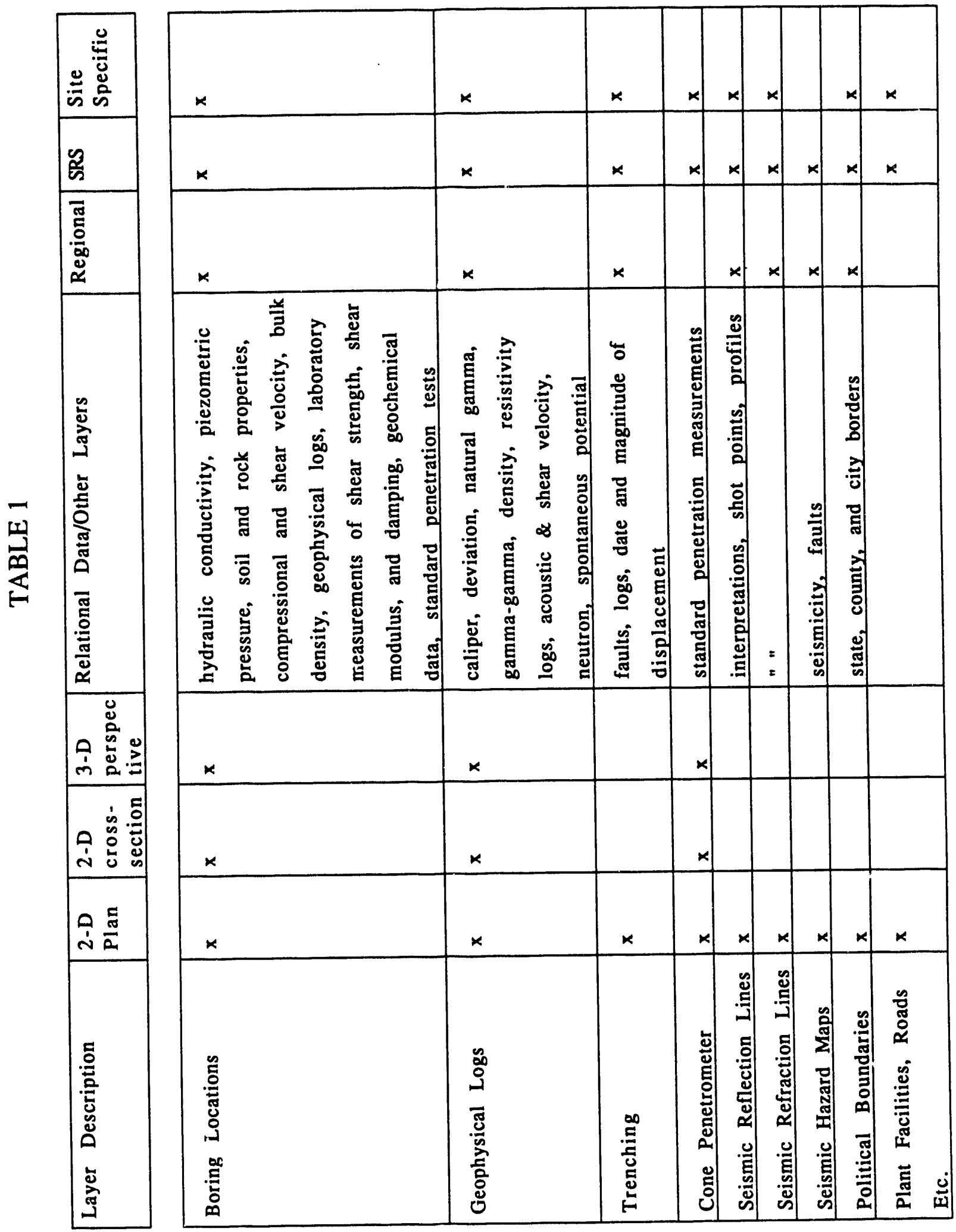




\section{Appendix III}

\section{Other Technical Requirements of GIS Software (typical ESRI)}

\section{Database}

- Use points, lines, and polygons to represent geographic features.

- Use labels with annotated text.

- Combine any features on a single map.

- Contain an integrated database management system for making correlation of cartographic and attribute data.

- Support a variety of data types for attribute values, including double precision coordinates, floating point numbers, integer numbers, character strings, and dates.

- Support up to 1000 files of unlimited size in a single database.

\section{Data Entry}

- Capabilities must include digitized points, lines, and polygons, and data converted from USGS Digital Line Graph (DLG) files, U.S. Census Bureau GBF/DIME files, grid data files, and scanner data.

- Must include automatic RMS error calculation and tic match tolerance.

- Interactively edit locational data with functions like copy, move, delete, undelete, modify, and add.

- Interactively define the content and format of the relational database.

- Support a data dictionary that identifies the database and its location.

Topology Generation, Data Editing, and Updating

- Allow user to interactively edit and update previously entered data.

\section{Data Manipulation and Analysis}

- Support overlaying coverages.

- Coordinate transformations, including scaling, shifting, and rotating a map feature.

- Support "rubber sheeting" coordinate transformations for stretching map feature coordinates.

- Support projection conversion transformations for numerous coordinate systems, including geographic (lat-lon), state plane coordinates, and Lambert Conformal Conic.
- Generate aggregates or subsets of maps by selecting map features with specified attributes.

- Selectively retrieve records that satisfy a Boolean combination of attributes.

- Manipulate features, attributes stored in tabular form independently of locational data.

- Support data conversions to and from the following formats: AMS, AutoCAD DXF files, ERDAS, ETAK, GIS systems (e.g., SIF, MOSS, COMPIS, GEOBASED, etc.), GBF/DIME and TIGER, GERBER, GIRAS, IGES, IMPELL, INGRES RDBI, NGS NAD83, and ORACLE RDBI.

- Describe and store 3-D surfaces as topological networks.

- Interface with digital elevation files.

- Create 3-D networks from existing digital terrain files, randomly or uniformly spaced data points, or contour line data.

- Generate contours, slope aspect, and surface area.

- Perform volume, cut-and-fill, watershed analyses.

- Interpolate surface data.

- Create cross sections.

\section{Data Output and Display}

- Generate graphic displays in both interactive and batch modes, for a variety of graphic terminals, and pen, electrostatic, and ink plotters.

- Save and edit map macros.

- Plot multiple coverages or database layers over one another.

- Window-to-viewport transformations for scaling, rotating, and positioning a map or maps; clip graphic elements.

- Query for map features and attributes.

- Perform relational operations during interactive graphic sessions for spatial query retrievals.

- Support over 1600 fonts and pattems.

- Support polygon shading.

- Position annotations with polygons, start point and angle, along line features, and at user specified locations.

- Provide interactive commands for creation of points, lines, arcs, and related geometric features.

- Manage coordinate data (points and figures).

- Use line and curve manipulating software, including location of azimuth, bearing angles, deflection, lines and arcs.

- Display tabular data associated with graphic objects, including basic coordinates, area, distance, azimuth bearings, traverse deflections, angles, etc. 


\section{Data Storage and Management}

- Use relational approach to data management.

- Log all changes made to a map with the date and time of the operation (transaction log or audit trail), connect time, CPU time and disk $\mathrm{I} / \mathrm{O}$, files, and file version numbers used in the construction. (Run logs automatically created in this manner will ensure map repeatability and error tracking.)

- Use standard database management system functions. 


\section{Appendix IV}

\section{Suggested Hardware/Software}

Workstation: Silicon Graphics Indigo w/ $32 \mathrm{Mb}$ memory; $1000 \mathrm{Mb}$ hard disk [suggested minimum memory and disk requirements for the $\mathrm{ARC} / \mathrm{INFO}$ and Dynamic Graphics Incorporated (DGI) software); 800

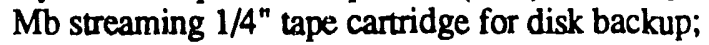
high-resolution color graphics monitor; ETHER Net.

Peripherals: Digitizer (full size, back-lit); Optical Disk (1 GB); CD-ROM drive; 9-tr tape drive (62.50 bpi), high-resolution color plotter.

\section{Operating System: UNIX}

Software: ESRI ARC/INFO (containing ARC COGO, for engineering applications, and TIN, for digital data manipulation); DGI ISM (complete); DGI IVM (complete); FORTRAN \& C (programming languages).

\section{Estimated Cost}

Approximate cost of hardware and software is $\$ 130,000$. Software maintenance is $10-15 \% / y r$. ETHER Net communications line installed to the WSRC VAX can be used to transfer data for additional backup purposes. 


\section{Appendix V}

$$
\begin{array}{lllllllllll}
\text { Quarter } & 1 & 2 & 3 & 4 & 5 & 6 & 7 & 8 & 9 & 10
\end{array}
$$

Task

1. Selection of GSG manager

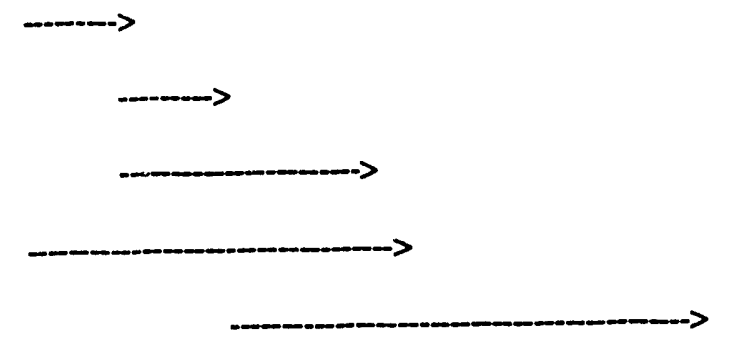

5. Development of initial SRS data layers

6. Development of regional data layers

7. Development of site-specific data layers

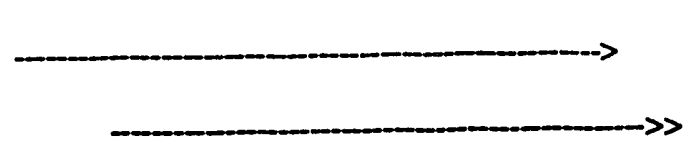

Schedule deliverables in the plan are dependent upon timely contractual arrangements to be made by WSRC Procurement. 

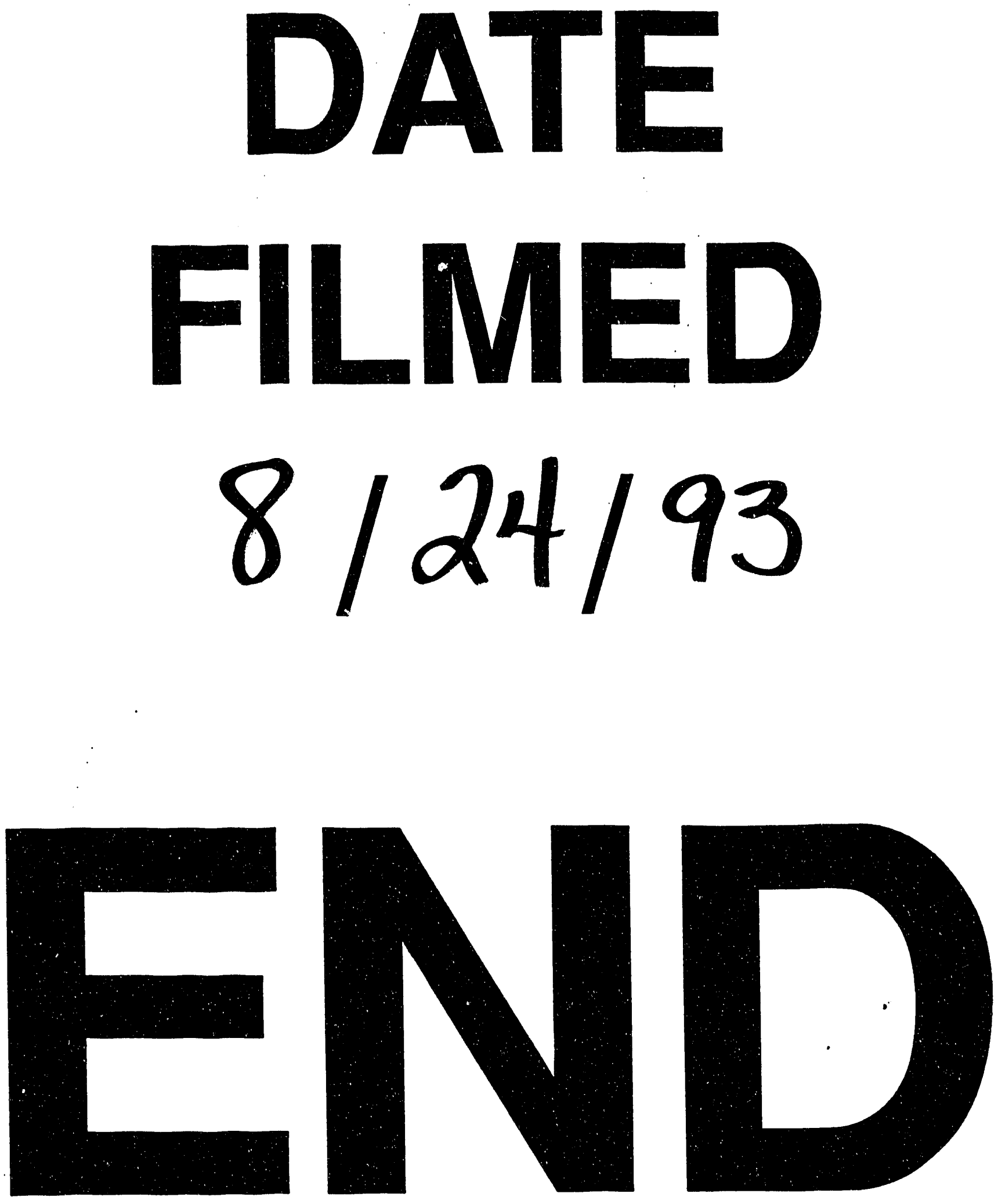
